\title{
Evaluating the crystallization of lactose at different cooling rates from milk and whey permeates in terms of crystal yield and purity
}

\author{
K. Pandalaneni and J. K. Amamcharla ${ }^{1}$ \\ Department of Animal Sciences and Industry/Food Science Institute, Kansas State University, Manhattan 66506
}

\begin{abstract}
The cooling rate of supersaturated lactose solution is one of the important parameters determining the yield and size distribution of lactose crystals. The influence of increasing cooling rate on lactose crystallization and quality of lactose crystals was evaluated in concentrated solutions prepared from deproteinized whey powder (DPW) and milk permeate powder (MPP). Concentrated permeates (DPW and MPP) with $60 \%$ (wt/wt) total solids were prepared by reconstituting permeate powders in water at $80^{\circ} \mathrm{C}$ for $2 \mathrm{~h}$ for lactose dissolution. Three cooling rates, $0.04^{\circ} \mathrm{C} / \mathrm{min}$ (slow), $0.06^{\circ} \mathrm{C} /$ min (medium), and $0.08^{\circ} \mathrm{C} / \mathrm{min}$ (fast) were studied in duplicate. A common rapid cooling step $\left(80\right.$ to $60^{\circ} \mathrm{C}$ at $0.5^{\circ} \mathrm{C} / \mathrm{min}$ ) followed by slow, medium, and fast cooling rates were applied as per the experimental design from 60 to $20^{\circ} \mathrm{C}$. After crystallization, the crystal slurry was centrifuged, washed with cold water, and dried. The dried lactose crystals were weighed to calculate the lactose yield. Final mean particle chord lengths were measured at the end of crystallization using focused beam reflectance measurement for slow, medium, and fast cooling rates, and observed to be not significantly different for DPW $(27-33 \mu \mathrm{m})$ and MPP $(31-34 \mu \mathrm{m})$ concentrates. Similarly, the lactose yield for slow, medium, and fast cooling rates in the DPW and MPP concentrates were in the range of 71 to $73 \%$ and 76 to $81 \%$, respectively, and no significant difference between the 3 cooling rates was found. Qualitative analysis of dried lactose crystals exhibited no noticeable differences in the crystal purity with increasing cooling rate. This study evaluated the possibility of reducing the crystallization times by $8 \mathrm{~h}$ compared with current industrial practice without compromising the crystal yield and quality.
\end{abstract}

Received March 29, 2018.

Accepted June 7, 2018.

${ }^{1}$ Corresponding author: Jayendra@ksu.edu
Key words: deproteinized whey, milk permeate powder, lactose crystal quality, focused beam reflectance measurement

\section{INTRODUCTION}

The growing demand for high-protein dairy ingredients led to fractionation of sweet whey and skim milk into a protein-rich fraction and protein-depleted fraction, often referred to as permeate. Milk permeate powder (MPP) and deproteinized whey (DPW) are the permeate fractions obtained during manufacturing of milk protein concentrate and whey protein concentrates, respectively, using UF and subsequent spray drying. Lactose is one of the major constituents in DPW and MPP, along with a small fraction of soluble minerals and proteins. Deproteinized whey is composed of 76 to $85 \%$ lactose, and 11 to $16 \%$ proteins and minerals, whereas MPP is composed of a higher lactose content of 78 to $88 \%$, with 11 to $16 \%$ proteins and minerals (US Dairy Export Council, 2015).

Lactose is used as an ingredient in infant formulations, food products, and the pharmaceutical industry and is manufactured using the crystallization process from whey and milk permeates. The aim of crystallization is to recover lactose in the most stable and nonhygroscopic $\alpha$-lactose monohydrate form and consequently prevent storage defects such as agglomeration and caking (Carpin et al., 2017). A typical lactose production at an industrial scale involves concentration of permeate to 60 to $65 \%$ TS followed by a gradual cooling, decantation, washing, and drying (Wong and Hartel, 2014). For an economical industrial production of lactose, maximum crystal yield is preferred. To avoid the loss of smaller crystals during decantation and washing steps, it is necessary to promote lactose crystal growth to maximize the lactose yield (Pandalaneni and Amamcharla, 2016).

Quality and yield of lactose are dependent on factors such as presence of impurities, agitation, cooling rate during crystallization, crystallizer design (Wong et al., 2012), and degree of supersaturation (McLeod et al., 
2011). Presence of whey proteins and minerals negatively affected the quality and yield of lactose (Modler and Lefkovitch, 1986; Lifran et al., 2007; Chandrapala et al., 2016), whereas additives like soybean polysaccharide significantly improved the lactose yield (Sunkesula et al., 2017). Crystallization is considered the most important step in lactose recovery that includes approximately $6 \mathrm{~h}$ to fill the crystallization tanks and 14 to $18 \mathrm{~h}$ for the crystallization process, accounting for a total of 20 to $24 \mathrm{~h}$ of processing (Wong et al., 2012). As the supersaturated solution is gradually cooled, lactose solubility decreases and the supersaturation drive increases. The supersaturation driving force is required for the formation of lactose crystals (McLeod et al., 2011). When supersaturated lactose solution is rapidly cooled, nucleation is dominant and the risk of obtaining lactose crystals with smaller particle size is high. On the other hand, when cooled slowly, lactose crystal nucleation and growth occur simultaneously, resulting in bigger lactose crystals (McLeod, 2007).

During crystallization, if nucleation is spontaneously induced by supersaturated lactose, it is referred to as homogeneous nucleation. On the other hand, if nucleation is induced by a foreign substance, it is called heterogeneous nucleation. Heterogeneous nucleation is also dependent on the solubility of impurities present in the solution (Mullin, 2001). During crystallization, along with lactose, impurities also settle on the lactose crystal lattice (Lifran et al., 2007). Impurities settled over the lactose crystals are removed during the crystal washing step, but impurities settled in the crystal lattice can affect the quality of lactose crystals. Hence, understanding the effect of cooling rate on the lactose crystallization in presence of impurities is critical.

Because information is lacking on the crystallization of lactose in whey permeate and milk permeate at concentrations relevant to industrial practice, this study was focused on characterizing the lactose crystallization and quality of lactose crystals at different cooling rates in concentrated permeates. One of the traditionally used cooling rates $\left(0.04^{\circ} \mathrm{C} / \mathrm{min}\right)$ was compared with relatively faster cooling rates using focused beam reflectance measurement (FBRM) and other techniques. The influence of cooling rate and naturally present impurities in the concentrated permeates on lactose crystallization and quality were evaluated in this study.

\section{MATERIALS AND METHODS}

\section{Experimental Design}

The effect of cooling rate during lactose crystallization in concentrated DPW and MPP solutions was studied at 3 levels: slow $\left(0.04^{\circ} \mathrm{C} / \mathrm{min}\right)$, medium $\left(0.06^{\circ} \mathrm{C} / \mathrm{min}\right)$, and fast $\left(0.08^{\circ} \mathrm{C} / \mathrm{min}\right)$. All the experiments were conducted randomly and in duplicate. One of the 3 cooling rates (slow, medium, and fast) was applied during cooling from 60 to $20^{\circ} \mathrm{C}$, accounting for the total crystallization period of $1,040,706$, and 540 min, respectively.

\section{Preparation of Supersaturated Lactose Solution from Permeates}

Deproteinized whey powder with $78.3 \%$ (dry basis) lactose and MPP with $86.6 \%$ (dry basis) lactose were acquired from Davisco Foods International Inc. (Le Seuer, MN) and Idaho Milk products (Jerome, ID), respectively. Concentrated DPW solution of $900 \mathrm{~g}$ with $60 \%$ (wt/wt) TS was prepared by gradually reconstituting $540 \mathrm{~g}$ of DPW into $360 \mathrm{~g}$ of distilled water at $80^{\circ} \mathrm{C}$ for $2 \mathrm{~h}$ under constant stirring. Complete dissolution of lactose was confirmed by microscopic examination. Concentrated MPP solution with 60\% TS was also prepared following the same procedure as described for concentrated DPW. Fully solubilized permeate solution was then transferred into a crystallizer maintained at $80^{\circ} \mathrm{C}$ and 1 of the 3 cooling rates was used to crystallize the lactose in a permeate system. No lactose seeds were added during the crystallization in this study.

\section{Experimental Setup and Lactose Crystallization}

Lactose Crystallization. Lactose crystallization was carried out in a custom-built double-jacketed crystallizer attached to a programmable water bath (Polystat Standard, Cole-Parmer, Court Vernon Hills, IL) as shown in Figure 1. A custom-made 4-blade anchor propeller was attached to an overhead stirrer (Caframo, Georgian Bluffs, Ontario, Canada) to facilitate the agitation. From preliminary experiments (data not reported), an agitation speed of $140 \mathrm{rpm}$ was selected to keep the crystals in suspension with minimal secondary nucleation due to breakage of crystals observed from microscopic images. A temperature probe connected to a data logger (HOBO, Bourne, MA) was used to acquire the crystallizer temperature every $10 \mathrm{~s}$. The crystallizer was covered with a lid to avoid any water loss. Three cooling rates were studied with a same initial flash cooling from 80 to $60^{\circ} \mathrm{C}$ at $0.5^{\circ} \mathrm{C} / \mathrm{min}$. The initial common cooling rate was used in this study to simulate flash cooling step commonly used in the industrial practice. For in situ monitoring of lactose crystallization, FBRM (Particle Track E25, Mettler-Toledo AutoChem Inc., Columbus, $\mathrm{OH}$ ) was installed in the crystallizer at a $30 \pm 5^{\circ}$ angle as described by Pandalaneni and Amamcharla (2016). 
Monitoring of Lactose Crystallization Using $\boldsymbol{F B R M}$. Focused beam reflectance measurement was used as an in situ monitoring tool during lactose crystallization in concentrated permeates. During crystallization, FBRM data were acquired for every $3{ }^{\circ} \mathrm{C}$ temperature drop from the pool of collected data. Particle chord lengths obtained from FBRM were categorized into $<50 \mu \mathrm{m}$ and 50 to $150 \mu \mathrm{m}$ and were referred to as fine and large particle counts, respectively. Particle chord length distribution (PCLD) was obtained at the end of lactose crystallization as described as Pandalaneni and Amamcharla (2016).

\section{Determination of Lactose Concentration}

A representative sample $(1 \mathrm{~mL})$ was withdrawn from the crystallizer at the beginning of crystallization $\left(80^{\circ} \mathrm{C}\right)$ and at $60^{\circ} \mathrm{C}$. Subsequently, a representative sample was also collected from the crystallizer at every $5^{\circ} \mathrm{C}$ temperature drop between 60 and $20^{\circ} \mathrm{C}$. The sample was diluted with $4 \mathrm{~mL}$ of chilled water $\left(5^{\circ} \mathrm{C}\right)$ and centrifuged at $3,000 \times g$ for $3 \mathrm{~min}$. The supernatant $(\sim 1 \mathrm{~mL})$ was further diluted with $7 \mathrm{~mL}$ of water to determine the lactose concentration using HPLC (HP 1050, Palo Alto, CA). Considering the dilution factor, the lactose concentration in the diluted sample was determined using the method described by Amamcharla and Metzger (2011) with some modifications. Lactose was separated using a $300 \times 7.80 \mathrm{~mm}$ ion exclusion column (ROA-Organic acid, Phenomenex, Rezex, Phenomenex Inc., CA) maintained at $50^{\circ} \mathrm{C}$ using filtered distilled water as a mobile phase at a flow rate of 0.6 $\mathrm{mL} / \mathrm{min}$. Lactose concentration was measured using refractive index detector (1047A, Hewlett-Packard, Palo Alto, CA) maintained at $50^{\circ} \mathrm{C}$.

Degree of Crystallization. Lactose concentrations obtained from HPLC were used to calculate the mass of crystals and extent of crystallization during the lactose crystallization following the same method as Pandalaneni and Amamcharla (2016).

Lactose Crystal Morphology. A sample volume of $1 \mathrm{~mL}$ was collected at every $5^{\circ} \mathrm{C}$ interval to determine crystal morphology. The sample was gently spread over a microscopic glass slide and images were acquired using a camera (Ken-a-vision, Kansas City, MO) attached to a compound microscope (American Optical, Depew, NY) at $10 \times$ magnification. The visual comparison was done to evaluate the influence of different cooling rates on the crystal growth and morphology. The glass slide was equilibrated to the crystallizer temperature to avoid rapid nucleation on the glass surface.

\section{Crystal Yield (\%)}

At the end of crystallization, the crystal slurry was transferred into 250-mL centrifuge tubes and centrifuged (Beckman, J2-21, Indianapolis, IN) at 9,820 $\times$ $g$ for $10 \mathrm{~min}$ at $5^{\circ} \mathrm{C}$. After centrifugation, the mother liquor was separated from crystals and $200 \mathrm{~g}$ of wash water at $5^{\circ} \mathrm{C}$ was added into the centrifuge tubes. Crystal slurry was thoroughly mixed and again centrifuged at $9,820 \times g$ for $5 \mathrm{~min}$ at $5^{\circ} \mathrm{C}$. This washing process

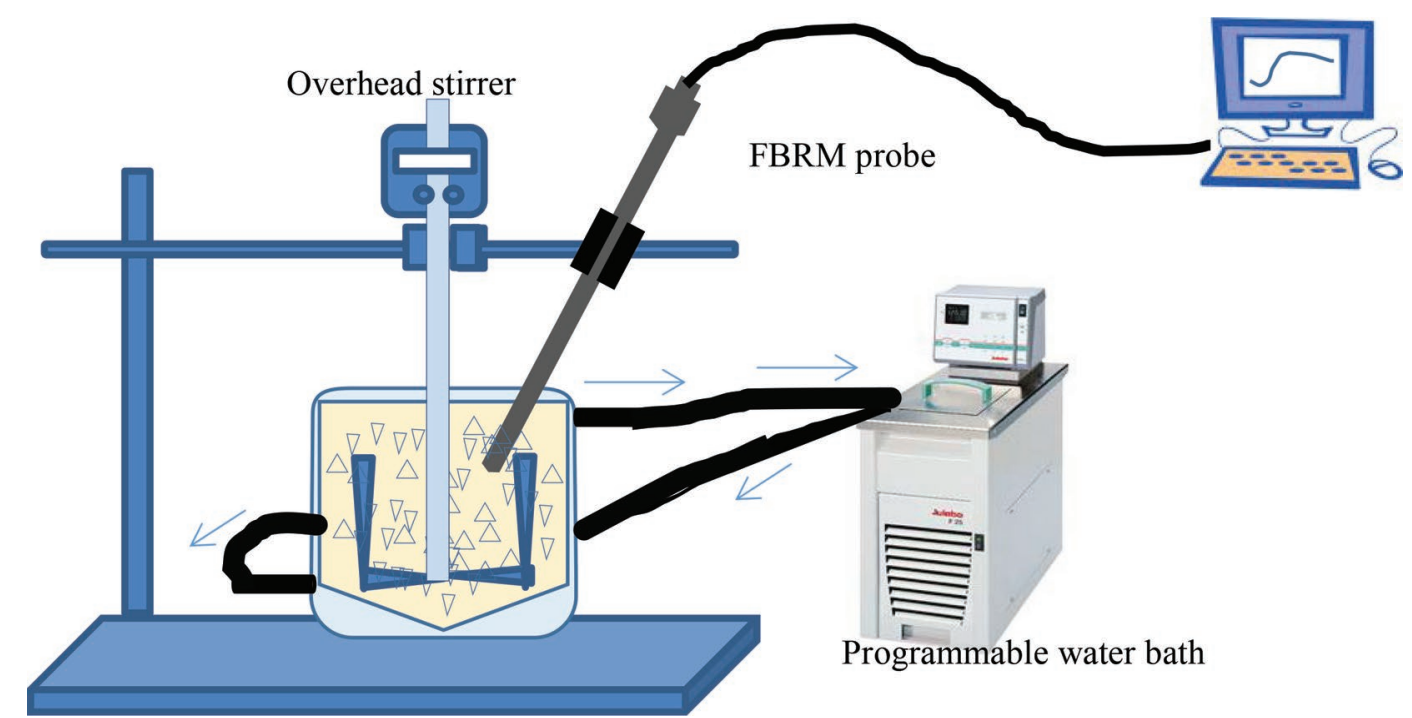

Figure 1. Experimental setup used in the study for controlled cooling of lactose solutions. FBRM = focused beam reflectance measurement. Color version available online. 
was repeated 3 times to obtain washed lactose crystals. Washed lactose crystals were dried in a forced-draft oven (Isotemp Oven, Fisher Scientific, Pittsburgh, PA) at $60^{\circ} \mathrm{C}$ for $14 \mathrm{~h}$. Dried lactose crystal weight was recorded and percentage yield of lactose was calculated using Equation [1]. The constant 0.95 was derived after removing $5 \%$ of the lactose crystal mass contributed by water molecules (Mimouni et al., 2005). Maximum theoretical yield was obtained by subtracting the concentration of lactose present in the solution at $20^{\circ} \mathrm{C}$ from the initial concentration of lactose in $60 \%$ TS permeate (Chandrapala et al., 2016).

$$
\begin{aligned}
& \text { Lactose crystal yield }(\%)= \\
& \frac{0.95 \times \text { Mass of dried crystals obtained }}{\text { Maximum theoretical crystal yield }} \times 100 \text {. }
\end{aligned}
$$

\section{Compositional Analysis}

Total solids percentage was determined using the oven drying method (AOAC International, 2002; method 990.20). Total nitrogen was determined following IDF Standard 185 (IDF, 2002) by the combustion method for nitrogen/protein determination. Ash content was determined after ignition of sample at $550^{\circ} \mathrm{C}$ (AOAC International, 2002; method 954.46). Trace minerals in dried lactose crystals were determined in the filtrate obtained by acid digestion $(6 \mathrm{~N} \mathrm{HCl})$ of ash. Filtrate was analyzed for $\mathrm{Ca}, \mathrm{K}, \mathrm{P}, \mathrm{Na}$, and $\mathrm{Mg}$ at wavelengths $220,766,820,589$, and $383 \mathrm{~nm}$, respectively, with inductively coupled plasma spectrophotometry (720-ES, Varian Australia Pvt. Ltd., Mulgrave, Australia; Chandrapala et al., 2015).

\section{Characterization of Dried Lactose Crystals}

Dried lactose crystals were characterized for crystal purity using a series of qualitative analysis including microscopic analysis, thermal analysis, and Fourier transform infrared spectroscopy (FTIR).

Crystal Purity. Impurities embedded in the lactose crystals were qualitatively analyzed using a method adapted from Butler (1998) with few modifications. Approximately $4 \mathrm{mg}$ of dried lactose crystals were suspended in 3 drops of refractive index solution on a microscopic slide and observed under a compound microscope. The refractive index solution with the same refractive index as lactose crystals (1.55) was custom ordered from Cargille Laboratories Inc. (Cedar Grove, NJ). Due to the same refractive index, the lactose crystals appeared translucent and any other impurities on the lactose crystals appeared as black spots in the microscopic images.
Differential Scanning Calorimetry. Thermal analysis of dried lactose crystals was conducted using a model Q2000 (TA Instruments, New Castle, DE). Approximately $5 \mathrm{mg}$ of the sample was weighed and sealed in hermetic aluminum pans and heated from temperatures 30 to $180^{\circ} \mathrm{C}$ at the rate of $10^{\circ} \mathrm{C} / \mathrm{min}$ (Shi and Zhong, 2014).

FTIR. Fourier transform infrared spectra of dried lactose crystals were obtained in the 400 to $4,000 \mathrm{~cm}^{-1}$ at a resolution of $4 \mathrm{~cm}^{-1}$ using a spectrometer (Cary 630, Agilent, Santa Clara, CA) with Micro Lab PC software. Absorbance mode was used for the analysis after subtracting the background spectra. Each spectrum was an average of 32 scans and all measurements were done in duplicate (Chandrapala et al., 2016). The FTIR spectra of pure lactose (99.8\% purity) obtained from Hilmar Ingredients (Turlock, CA), DPW, and MPP powders were also acquired and compared with the dried lactose crystals recovered from the respective sources.

\section{Statistical Analysis}

Statistical analysis was performed using SAS software (v 9.1). One-way ANOVA and Tukey's test were conducted to compare the significant differences in parameters measured between cooling rates and were declared significant if $P \leq 0.05$.

\section{RESULTS AND DISCUSSION}

\section{Effect of Cooling Rate on Desupersaturation of Lactose}

This section summarizes the effect of slow, medium, and fast cooling rates on the rate at which desupersaturation progressed in concentrated permeates. As the permeate concentrate is cooled, the equilibrium between $\alpha$ and $\beta$ forms of lactose in solution is disturbed, resulting in mutarotation of $\beta$-lactose to $\alpha$-lactose. This sequence of transformation of $\alpha$-lactose to $\alpha$-lactose monohydrate followed by mutarotation of $\beta$-lactose to $\alpha$-lactose occurs until an equilibrium is established (Gänzle et al., 2008).

DPW Concentrate. The initial mean concentration of lactose in $60 \%$ DPW concentrates were in the range of 47.28 to $48.55 \%$ as shown in Table 1. Desupersaturation curve of lactose during crystallization in DPW exhibited a similar trend as observed in the literature (Mullin, 2001; Goulart and Hartel, 2017) with an initial induction period, followed by a rapid decrease in the lactose concentration, and reached a steady decrease toward the end of crystallization as shown in Figure 2A. This nucleation phenomenon during the induction time 
was explained by Mullin (2001) in 3 stages: relaxation time (time required to form clusters of nuclei from the imposed supersaturation), followed by nucleation time (time required to form a stable nucleus), and growth time (time required to grow to a detectable size). During lactose crystallization, desupersaturation of lactose continues to occur during nucleation followed by crystal growth until the lactose concentration reaches the equilibrium at the end of crystallization process.

During the initial common cooling phase from 80 to $60^{\circ} \mathrm{C}$, lactose concentration decreased from an average concentration of 47.26 to $44.8 \%$ across the 3 cooling rates studied. The induction period was followed by a rapid desupersaturation of lactose from 60 to $50^{\circ} \mathrm{C}$ with an average decrease in lactose concentration from 43.8 to $26.42 \%$ for the 3 cooling rates studied. The time taken for slow, medium, and fast cooling rates to reach the same extent of desupersaturation (from 43.8 to $26.42 \%$ ) was 227,148 , and $106 \mathrm{~min}$, respectively. This implies that irrespective of the cooling rate used for lactose crystallization, the extent of desupersaturation was similar in DPW concentrates. A slow but steady decrease in lactose supersaturation was observed from 50 to $20^{\circ} \mathrm{C}$ because of the reduced supersaturation driving force as the lactose concentration approached a phase equilibrium (Goulart and Hartel, 2017). The decrease in lactose concentration observed was from $26.42 \%$ at $50^{\circ} \mathrm{C}$ to an average of $22.50 \%$ at $20^{\circ} \mathrm{C}$ for the 3 cooling rates studied. The degree of crystallization at the end of the crystallization in DPW permeates using 3 cooling rates studied was not significantly different $(P>0.05)$, as shown in Table 2 . It was evident from the Figure 2A and degree of crystallization (Table 2) that desupersaturation of lactose was not influenced by the cooling rates during lactose crystallization in DPW concentrate.

MPP Concentrate. The initial mean concentration of lactose in $60 \%$ MPP concentrate has in the range of 51.71 to $52.07 \%$ as shown in Table 1. The desupersaturation curve of lactose during crystallization in MPP concentrates (Figure 2B) also exhibited a similar behavior as desupersaturation curve of DPW concentrates (Figure 2A). Desupersaturation curve of MPP concentrates also exhibited an induction period, rapid decrease in lactose concentration, followed by a slow and steady decrease toward the end of crystallization. As the cooling progressed from 80 to $60^{\circ} \mathrm{C}$ during lactose crystallization, the average drop in lactose concentration during 3 cooling rate studies was observed from 51.13 to $48.87 \%$. As the cooling rates started from 60 to $20^{\circ} \mathrm{C}$, a rapid decrease in the lactose concentration was observed from 60 to $40^{\circ} \mathrm{C}$. The average decrease in the lactose concentration was from 48.87 to $25.8 \%$ across all the cooling rates. It is noteworthy to mention that the
Table 1. Mean \pm SD of TS, lactose, protein, and ash from $60 \%$ deproteinized whey (DPW) and milk permeate powder (MPP) concentrates

\begin{tabular}{lrr}
\hline Composition & DPW (\%) & \multicolumn{1}{c}{ MPP (\%) } \\
\hline TS & $57.61 \pm 0.42$ & $57.81 \pm 0.52$ \\
Lactose & $48.03 \pm 0.67$ & $51.85 \pm 0.19$ \\
Protein & $3.53 \pm 0.03$ & $2.29 \pm 0.07$ \\
Ash & $5.36 \pm 0.07$ & $4.75 \pm 0.08$ \\
\hline
\end{tabular}

time accounted for slow, medium, and fast cooling rates to reach the same extent of desupersaturation $(48.87$ to $25.8 \%$ ) was 507,298 , and $228 \mathrm{~min}$, respectively. The desupersaturation curve exhibited a slow and steady decrease in toward the end of crystallization from 40 to $20^{\circ} \mathrm{C}$ because of the decrease in the supersaturation drive as the phase equilibrium is reached. Thus, the average decease in lactose concentration observed was from 25.8 to $21.99 \%$. The degree of crystallization obtained at the end of the crystallization as shown in Table 2 was not significantly different $(P>0.05)$ between the 3 cooling studies studied. The overall observation made from Figure $2 \mathrm{~B}$ and the degree of crystallization (Table 2) was that the desupersaturation was not influenced by the slow, medium, and fast cooling rates during lactose crystallization.

When desupersaturation curves of DPW and MPP concentrates were compared (Figures $2 \mathrm{~A}$ and $2 \mathrm{~B}$ ), a noteworthy difference in the decrease in lactose concentration was observed during 60 to $50^{\circ} \mathrm{C}$ cooling, irrespective of cooling rates. A rapid decrease in lactose concentration from 43.8 to $26.42 \%$ was observed in DPW concentrates, whereas a decrease from 48.87 to $34.69 \%$ was observed in MPP concentrates. This rapid desupersaturation in DPW concentrates can be attributed to the presence of higher percentage of proteins and minerals when compared with MPP concentrates as shown in Table 1. The presence of proteins increased the nucleation due to their hydrophilic properties in supersaturated lactose solutions. As whey proteins bind to water molecules, localized supersaturation spots were formed and consequently created favorable conditions for nucleation (Mimouni et al., 2005). Along with proteins, minerals also contributed to improve the lactose crystal growth rate during lactose crystallization (Bhargava and Jelen, 1996). When degree of crystallization was compared (Table 2), it was evident from the 3 cooling rates studied that MPP concentrates have a higher degree of crystallization than DPW concentrates. This can be attributed to the higher initial lactose concentration in MPP concentrates, which increased the supersaturation drive, thereby increasing the degree of crystallization. 


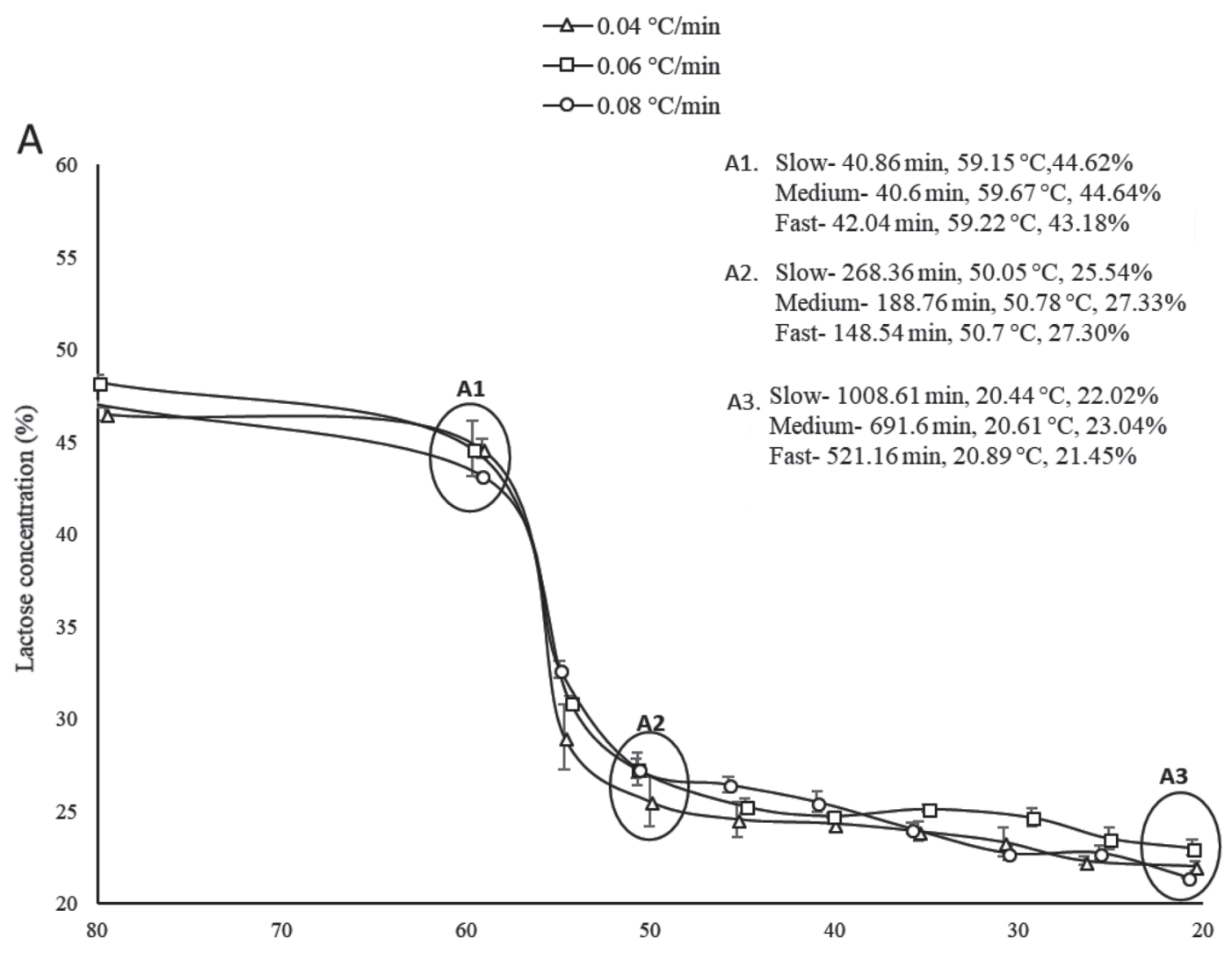

B

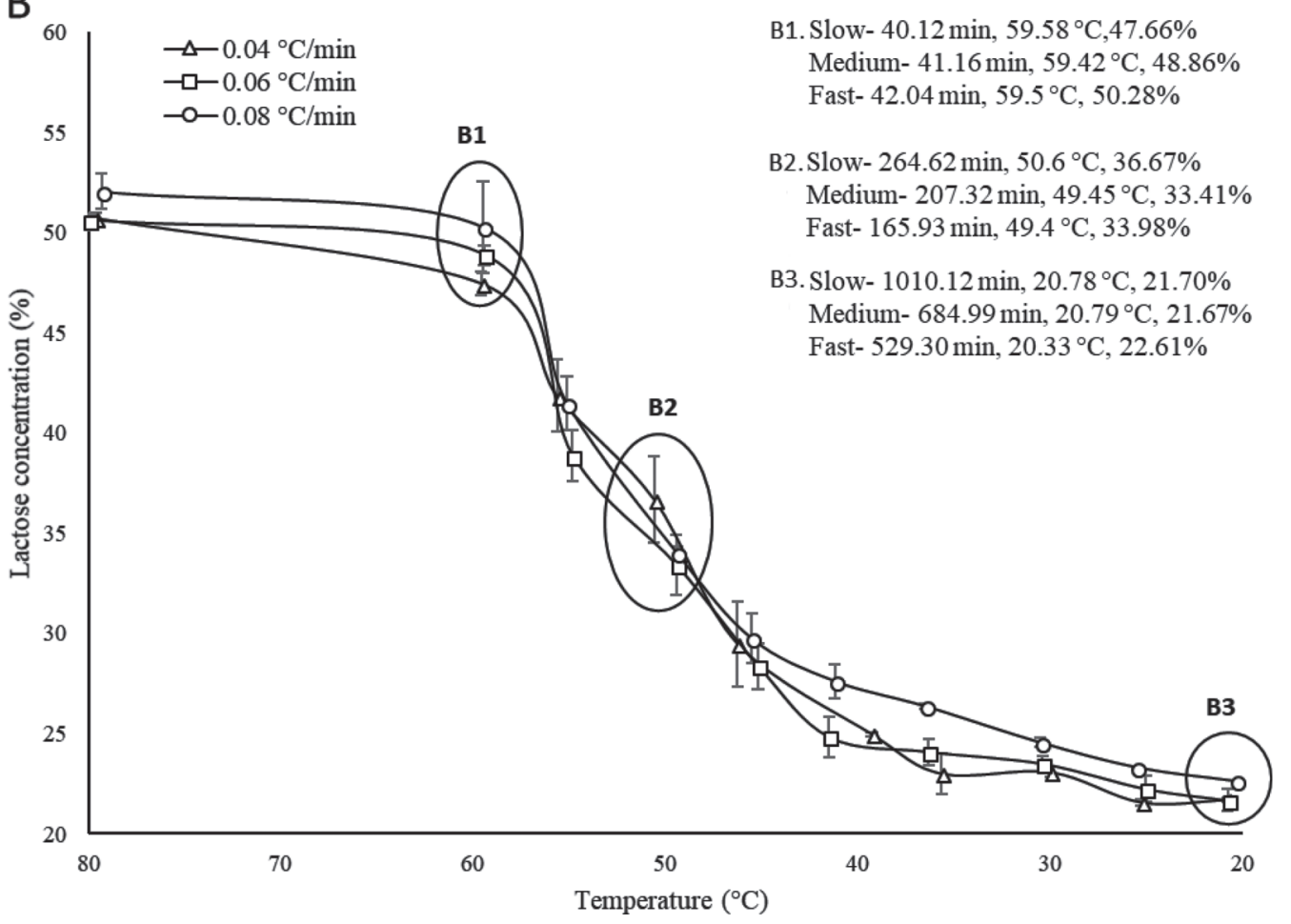

Figure 2. Desupersaturation of lactose during lactose crystallization in (A) deproteinized whey (DPW) and (B) milk permeate powder (MPP) concentrates using $0.04^{\circ} \mathrm{C} / \mathrm{min}$ (slow), $0.06^{\circ} \mathrm{C} / \mathrm{min}$ (medium), and $0.08^{\circ} \mathrm{C} / \mathrm{min}$ (fast) cooling rate. Time, temperature, and lactose concentration at 3 selected points during crystallization in DPW (A1, A2, and A3) and MPP (B1, B2, and B3) concentrates. Error bars represent $\mathrm{SD}(\mathrm{n}=2)$. 


\section{Evaluation of FBRM Data}

In this study, the progress of lactose crystallization in the concentrated DPW and MPP solutions was evaluated using FBRM. Focused beam reflectance measurement is an efficient in situ tool for monitoring changes in particle counts and growth during lactose crystallization (Pandalaneni and Amamcharla, 2016). However, it cannot differentiate between lactose crystals and other impurities present in suspension. Hence, the results were interpreted as particle counts in contrary to crystal counts in a previous study (Pandalaneni and Amamcharla, 2016). During 3 cooling rates, particle counts were grouped into fine $(<50 \mu \mathrm{m})$ and large $(50-150$ $\mu \mathrm{m})$ to evaluate the changes in particle sizes during lactose crystallization.

Particle Counts in DPW. In DPW concentrate, any particle counts at the beginning of the experiment at $80^{\circ} \mathrm{C}$ was due to the presence of air bubbles and calcium phosphate precipitates at higher temperatures, as shown in Figure 3A. Butler (1998) also observed calcium phosphate residual lumps in concentrated permeates because of its lower solubility in aqueous solution. The protein fraction in DPW concentrates also precipitated at higher temperatures, along with calcium phosphate (Chandrapala et al., 2015), contributing to large particle counts. This phenomenon was supported by the microscopic images confirming the absence of lactose nuclei or crystals in DPW concentrates at the beginning at $80^{\circ} \mathrm{C}$. A typical microscopic image observed at the beginning of crystallization during 3 cooling rates is shown in Figure 4A.

As shown in Figures $3 \mathrm{~A}$ and $3 \mathrm{~B}$, during the common cooling step $\left(80-60^{\circ} \mathrm{C}\right)$, fine particle counts steadily increased while large particle counts decreased. These changes in the fine and large particle counts can be attributed to the solubilization and breakage of mineral precipitates due to agitation and cooling. With the decrease in temperature, the solubility of lactose also decreased and resulted in the increased supersaturation driving force. Increase in supersaturation driving force and agitation promoted the lactose nucleation, contributing to increase in fine particle counts. At $60^{\circ} \mathrm{C}$, small clusters of nuclei were observed in the microscopic images (Figure 4B) because of the diffusion of lactose from the liquid phase to solid phase; however, lactose nuclei clusters were in relaxation phase of induction time during the common cooling step of lactose crystallization (Mullin, 2001). The sequence of microscopic images shown in Figure 4 illustrates the nucleation and growth behavior of lactose. From the image at $60^{\circ} \mathrm{C}$ (Figure 4B), the nuclei clusters and a few stable tomahawk-shaped nuclei can be observed, along with some air bubbles.

As the cooling progressed during the lactose crystallization, fine particle counts rapidly increased and reached a local peak at approximately 65,000 counts in the temperature range of 57 to $55^{\circ} \mathrm{C}$ in all 3 cooling rates studied. This rapid increase was followed by a drastic decrease in fine particle counts to approximately 56,000 during the temperature range of 55 to $51^{\circ} \mathrm{C}$. The local peaks of fine particle counts can be attributed to rapid nucleation (Figure 3A), and the following decrease was because of the growth of formed lactose nuclei (Figure 3B). Lactose crystal growth was also evident from increased large particle counts during temperature range of 55 to $54^{\circ} \mathrm{C}$. A sudden desupersaturation of lactose (Figure 2A) in the temperature range of 57 to $50^{\circ} \mathrm{C}$ suggested that the diffusion of lactose from liquid phase to the solid phase was rapid, supporting the particle count results observed from FBRM data. These rapid changes can be better explained using the classical

Table 2. Mean $\pm \mathrm{SD}$ of degree of crystallization, final mean particle chord length (PCL), and the lactose crystal yield at the end of lactose crystallization from deproteinized whey (DPW) and milk permeate powder (MPP) concentrates

\begin{tabular}{lcccc}
\hline Item & $\begin{array}{c}\text { Total crystallization } \\
\text { time (min) }\end{array}$ & $\begin{array}{c}\text { Degree of } \\
\text { crystallization }(\%)\end{array}$ & $\begin{array}{c}\text { Final mean } \\
\text { PCL }(\mu \mathrm{m})\end{array}$ & $\begin{array}{c}\text { Lactose } \\
\text { yield }(\%)\end{array}$ \\
\hline $\mathrm{DPW}$ & & & & \\
$0.04^{\circ} \mathrm{C} / \min$ & 1,008 & $82.0 \pm 0.8^{\mathrm{a}}$ & $33.22 \pm 2.43^{\mathrm{a}}$ & $73.70 \pm 0.28^{\mathrm{a}}$ \\
$0.06^{\circ} \mathrm{C} / \min$ & 691 & $81.4 \pm 1.55^{\mathrm{a}}$ & $30.29 \pm 5.13^{\mathrm{a}}$ & $71.35 \pm 3.75^{\mathrm{a}}$ \\
$0.08^{\circ} \mathrm{C} / \min$ & 521 & $83.9 \pm 1.99^{\mathrm{a}}$ & $27.05 \pm 3.04^{\mathrm{a}}$ & $72.70 \pm 1.13^{\mathrm{a}}$ \\
$\mathrm{MPP}$ & & & & \\
$0.04^{\circ} \mathrm{C} / \min$ & 1,010 & $98.4 \pm 0.44^{\mathrm{A}}$ & $32.08 \pm 0.12^{\mathrm{A}}$ & $79.65 \pm 2.44^{\mathrm{A}}$ \\
$0.06^{\circ} \mathrm{C} / \min$ & 684 & $98.6 \pm 0.35^{\mathrm{A}}$ & $31.91 \pm 5.73^{\mathrm{A}}$ & $81.40 \pm 4.10^{\mathrm{A}}$ \\
$0.08^{\circ} \mathrm{C} / \min$ & 529 & $96.3 \pm 0.09^{\mathrm{A}}$ & $34.61 \pm 0.59^{\mathrm{A}}$ & $76.84 \pm 0.24^{\mathrm{A}}$ \\
\hline
\end{tabular}

${ }^{a}$ Values with the same superscript are not significantly different $(P>0.05)$. Lowercase superscripts were used to compare values from lactose crystallization experiments in DPW concentrate.

${ }^{A}$ Values with the same superscript are not significantly different $(P>0.05)$. Uppercase superscripts were used to compare values from lactose crystallization experiments in MPP concentrate. 


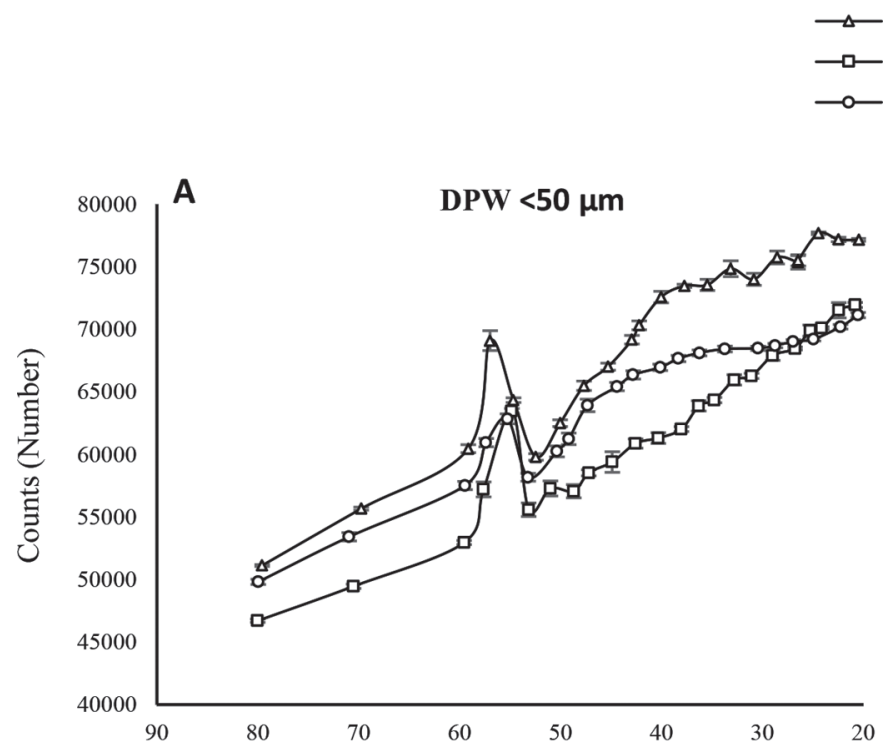

$\triangle-0.04^{\circ} \mathrm{C} / \mathrm{min}$

ㄴ $0.06^{\circ} \mathrm{C} / \mathrm{min}$

$-0-0.08^{\circ} \mathrm{C} / \mathrm{min}$
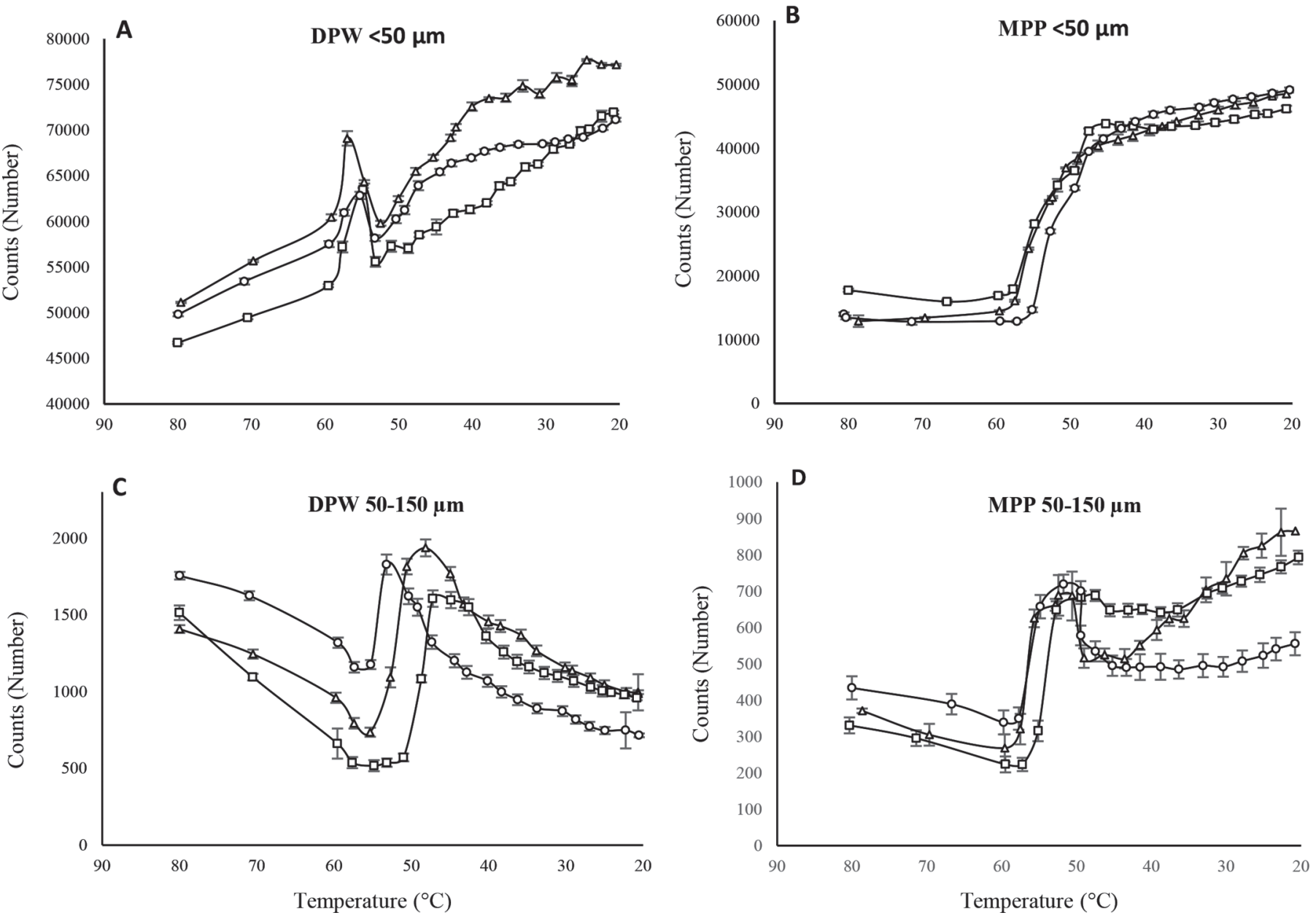

Figure 3. Fine $(<50 \mu \mathrm{m} ; \mathrm{A}, \mathrm{B})$ and large $(50-150 \mu \mathrm{m}$; C, D) particle counts data obtained from focused beam reflectance measurement $(\mathrm{FBRM})$ during lactose crystallization in deproteinized whey (DPW) and milk permeate powder $(\mathrm{MPP})$ concentrates using $0.04^{\circ} \mathrm{C} / \mathrm{min}(\mathrm{slow})$, $0.06^{\circ} \mathrm{C} / \mathrm{min}$ (medium), and $0.08^{\circ} \mathrm{C} / \mathrm{min}$ (fast) cooling rates. Error bars represent $\mathrm{SD}(\mathrm{n}=2)$.

nucleation theory (McLeod et al., 2011). According to this theory, the diffused lactose from the liquid phase is more prone to settle down on the available crystal surface than form new nuclei. Due to the presence of impurities, diffused lactose used impurity precipitates as a seed to form nuclei, referred to as heterogeneous nucleation. Heterogeneous nucleation occurs more easily because of the reduced energy barrier required for the creation of new solid-liquid interface (McLeod et al., 2011). The 3 cooling rates did not show any influence on rapid nucleation, as evident from fine particle counts and the desupersaturation of lactose (Figure $2 \mathrm{~A})$. However, variation in the increase of large particle counts suggested that the lactose crystal growth changed depending on the cooling rate used during the lactose crystallization. There was an increase of 1,200 , 1,035, and 651 large particle counts during cooling from 57 to $48^{\circ} \mathrm{C}$ when slow, medium, and fast cooling rates were used, respectively.

Increased large particle counts during 57 to $48^{\circ} \mathrm{C}$ led to an increase in the population density of lactose crystals, resulting in the breakage of crystals either by collision into walls of the crystallizer or the impeller. As a result, the increase in fine particle counts and decrease in large particle counts was observed simultaneously as shown in Figures 3A and 3B. The attrition and breakage of crystals further promoted secondary nucleation and allowed lactose to diffuse on to the already formed 
crystal lattice (McLeod et al., 2011). The progressive increase in the fine particle counts as the cooling progressed was more prominent in the fast cooling rate compared with the medium and slow cooling rates. In large particle counts, slow and medium cooling rates were in the same range and had approximately 200 counts more than the fast cooling rate. These observations summarize that the nucleation was not influenced by the 3 cooling rates studied. However, the lactose crystal growth was favored by the slow cooling rate in the DPW concentrate.

Particle Counts in MPP. In the MPP concentrate, the absence of lactose nuclei at the beginning of crystal-

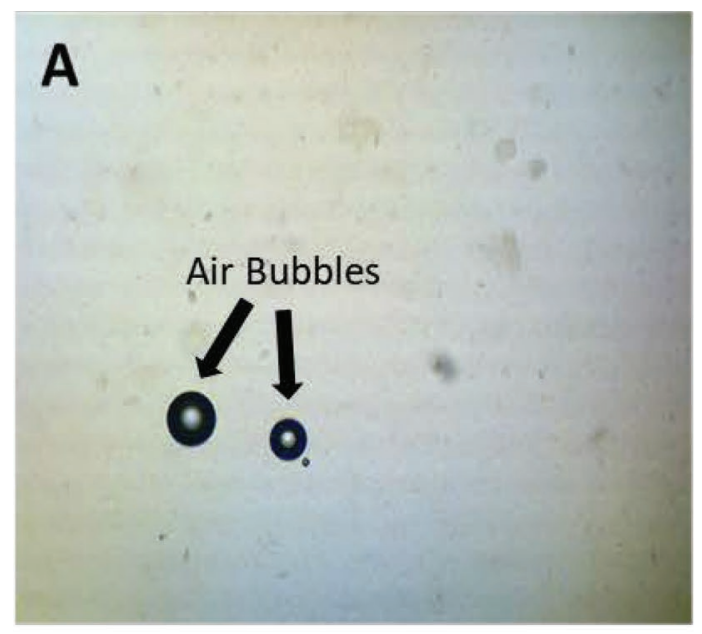

\section{$80^{\circ} \mathrm{C}$}

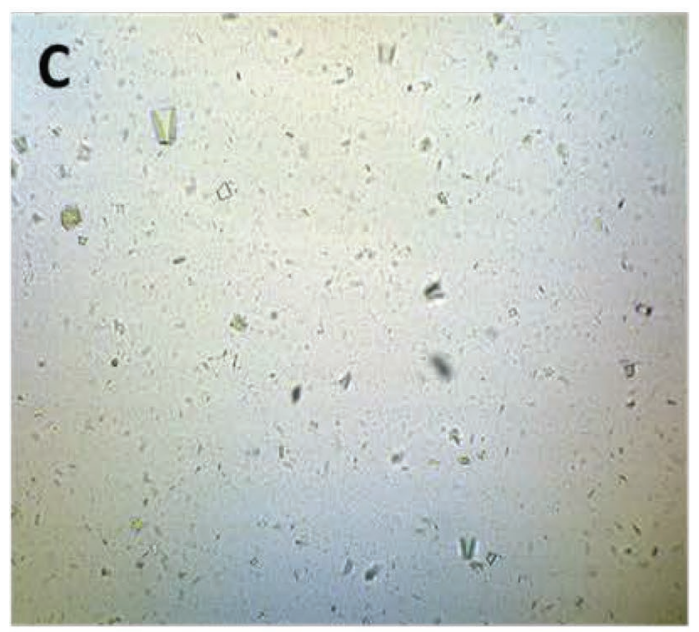

$55^{\circ} \mathrm{C}$ lization at $80^{\circ} \mathrm{C}$ was confirmed with the microscopic images as well. However, a contrasting behavior of particle counts was observed compared with the DPW concentrates. Fewer fine and large particle counts were observed in the MPP concentrate at $80^{\circ} \mathrm{C}$ compared with DPW concentrate. Lower ash and protein content in MPP concentrates compared with the DPW concentrates (Table 1) reduced the influence of mineral and protein precipitates on large particle counts at $80^{\circ} \mathrm{C}$. In concentrated DPW solutions with $60 \%$ TS, average protein and mineral percentages were 3.5 and $5.3 \%$, respectively. However, in concentrated MPP solutions with $60 \%$ TS, measured protein and mineral percent-

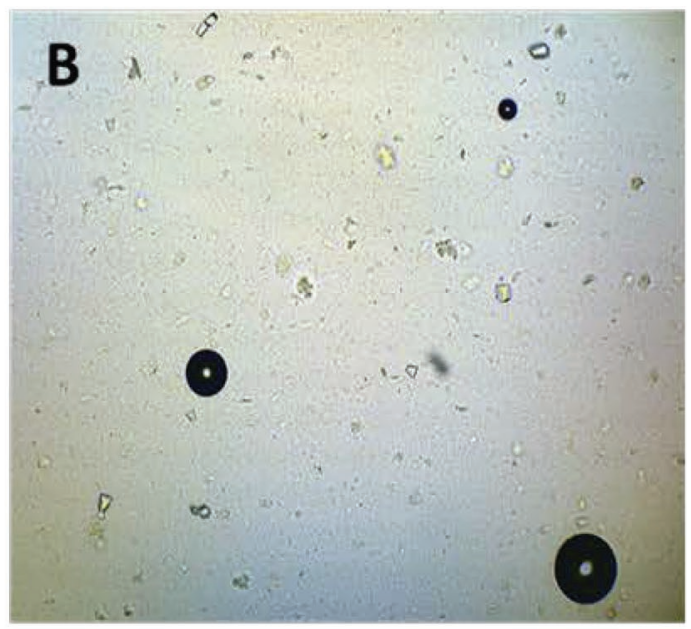

$60^{\circ} \mathrm{C}$

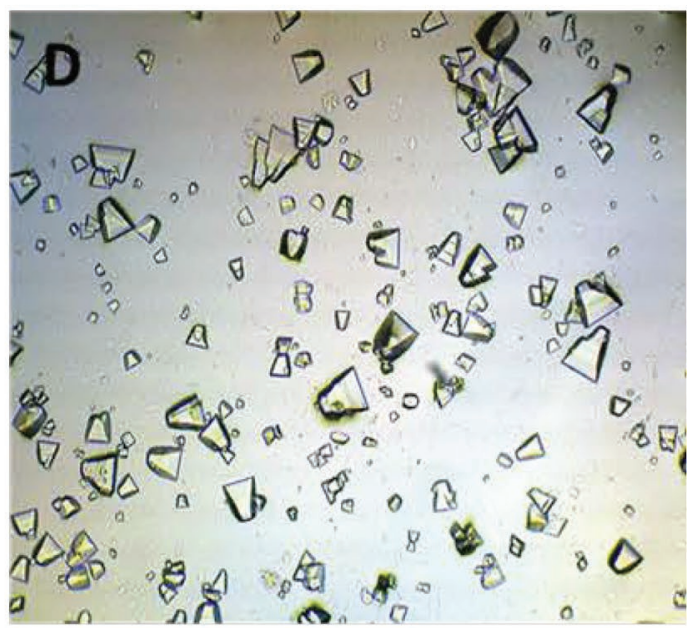

$50^{\circ} \mathrm{C}$

Figure 4. Typical microscopic images acquired at $80(\mathrm{~A}), 60(\mathrm{~B}), 55(\mathrm{C})$, and $50^{\circ} \mathrm{C}(\mathrm{D})$ to understand the changes observed in the particle counts of focused beam reflectance measurement during lactose crystallization in concentrated deproteinized whey (DPW)/milk permeate powder (MPP). (A) No lactose nuclei, only air bubbles present, (B) lactose nuclei, (C) lactose nuclei and some crystal growth, and (D) growth of lactose crystals. Color version available online. 
ages were in the range of 2.3 and $4.7 \%$, respectively. As the cooling progressed, fine particle counts in the MPP concentrate exhibited a slight increase in number, but large particle counts decreased because of the mineral solubilization and breakage. As the MPP concentrate was cooled from 80 to $60^{\circ} \mathrm{C}$, lactose nuclei clusters were observed in the MPP concentrate similar to crystals shown in Figure 4B, along with a decrease in lactose concentration. The particle counts of the concentrated DPW and MPP solutions strengthened the assumption that the presence of impurities and their solubilization properties were dominant as the concentrates were cooled. Both DPW and MPP concentrates were in induction time until temperature reached to approximately $60^{\circ} \mathrm{C}$, as evident from the desupersaturation curve (Figure 2) and the FBRM counts (Figures 3C and 3D).

The particle counts of the MPP concentrate followed a different trend, compared with the DPW concentrate after the 80 to $60^{\circ} \mathrm{C}$ cooling (common cooling step). No intermediate peak or drastic drop occurred in fine and large particle counts at any of the cooling rates studied. The change in the behavior of the lactose crystal nucleation and growth can be attributed to the minimum heterogeneous nucleation due to low impurity content compared with the DPW concentrate. The ratio of lactose to protein and ash percentage in DPW and MPP concentrates at $60 \%$ TS was approximately 5.4 and 7.4, respectively (Table 1 ). The continuous increase of fine and large particle counts at approximately $57^{\circ} \mathrm{C}$ imply that lactose crystal nucleation and crystal growth occurred simultaneously, irrespective of the cooling rate studied. Due to the higher lactose concentration in the MPP concentrate $(\sim 52 \%)$ at the $60 \%$ TS, the supersaturation drive was high, resulting in both nucleation and crystal growth to occur simultaneously. A steady decrease in the lactose concentration from $48.8 \%$ at $60^{\circ} \mathrm{C}$ to $25.8 \%$ at $40^{\circ} \mathrm{C}$ was observed in MPP concentrate (Figure 2B) in contrast to the rapid decrease in DPW concentrate (Figure 2A). This observation also supported the hypothesis that rapid nucleation was absent in the MPP concentrates at 3 cooling rates.

After an increase in particle counts by nucleation and crystal growth, a steady increase in the fine and coarse counts was observed from approximately $48^{\circ} \mathrm{C}$, representing the primary nucleation and secondary nucleation at all the 3 cooling rates. However, the decrease in the large particle counts in MPP concentrate was not as prominent as in the DPW concentrate. This implies that crystal growth was more dominant in MPP concentrate along with some secondary nucleation that occurred due to the crystal attrition and breakage.
Only large particle counts were influenced by the slow, medium, and fast cooling rates thereafter, because slower cooling rate favored the lactose crystal growth.

\section{Evaluation of PCLD and Microscopic Analysis}

Focused beam reflectance measurement is a helpful tool to determine the PCLD of the total particle population present in the crystallizer without any sample preparation. The final mean of particle counts obtained during the 3 cooling rates from PCLD was compared in DPW and MPP concentrates at the end of crystallization. The final means of particle counts in the DPW concentrate for slow, medium, and fast cooling rates were $33.22,30.29$, and $27.05 \mu \mathrm{m}$, respectively (Table 2 ). However, the final mean of particle counts in the MPP concentrate for slow, medium, and fast cooling rates were $32.08,31.91$, and $34.61 \mu \mathrm{m}$, respectively. No significant difference $(P>0.05)$ was observed between the final mean of particle counts when slow, medium, and fast cooling rates were applied during the crystallization in DPW and MPP concentrates. Chord length distribution of lactose crystals obtained after $10 \mathrm{~h}$ of isothermal crystallization $\left(20^{\circ} \mathrm{C}\right)$ in 50,55 , and $60 \%$ of pure lactose was reported as 58.10, 41.66, and 39.12 $\mu \mathrm{m}$, respectively (Pandalaneni and Amamcharla, 2016). The difference in the final chord length of distribution in pure lactose system and in permeates system can be attributed to presence of impurities that hinder the rate of crystal growth (Bhargava and Jelen, 1996; Mimouni et al., 2005).

The PCLD of 3 cooling rates obtained for DPW and MPP concentrates is shown in Figure 5. The PCLD was obtained using FBRM at the end of crystallization to demonstrate the influence of cooling rates on the particle distribution in the crystallizer. From Figure 5, it was evident that the PCLD of slow, medium, and fast cooling rates had similar distribution at the end of crystallization. The PCLD data were further supported by the microscopic images of lactose crystals taken at the end of lactose crystallization as shown in Figure 6. It is evident that the lactose crystals did not show any noticeable size differences during the 3 cooling rates and exhibited a similar size distribution.

Lactose crystal slurry obtained at the end of crystallization was dried and weighed to calculate the lactose yield (\%) using Equation 1. The lactose yield obtained using the 3 cooling rates were in the range of 71 to $73 \%$ and 76 to $81 \%$ in DPW and MPP concentrates, respectively, as shown in Table 2. The lactose yields obtained in 3 cooling rates were not significantly different $(P>0.05)$ in both the permeate concentrates. 

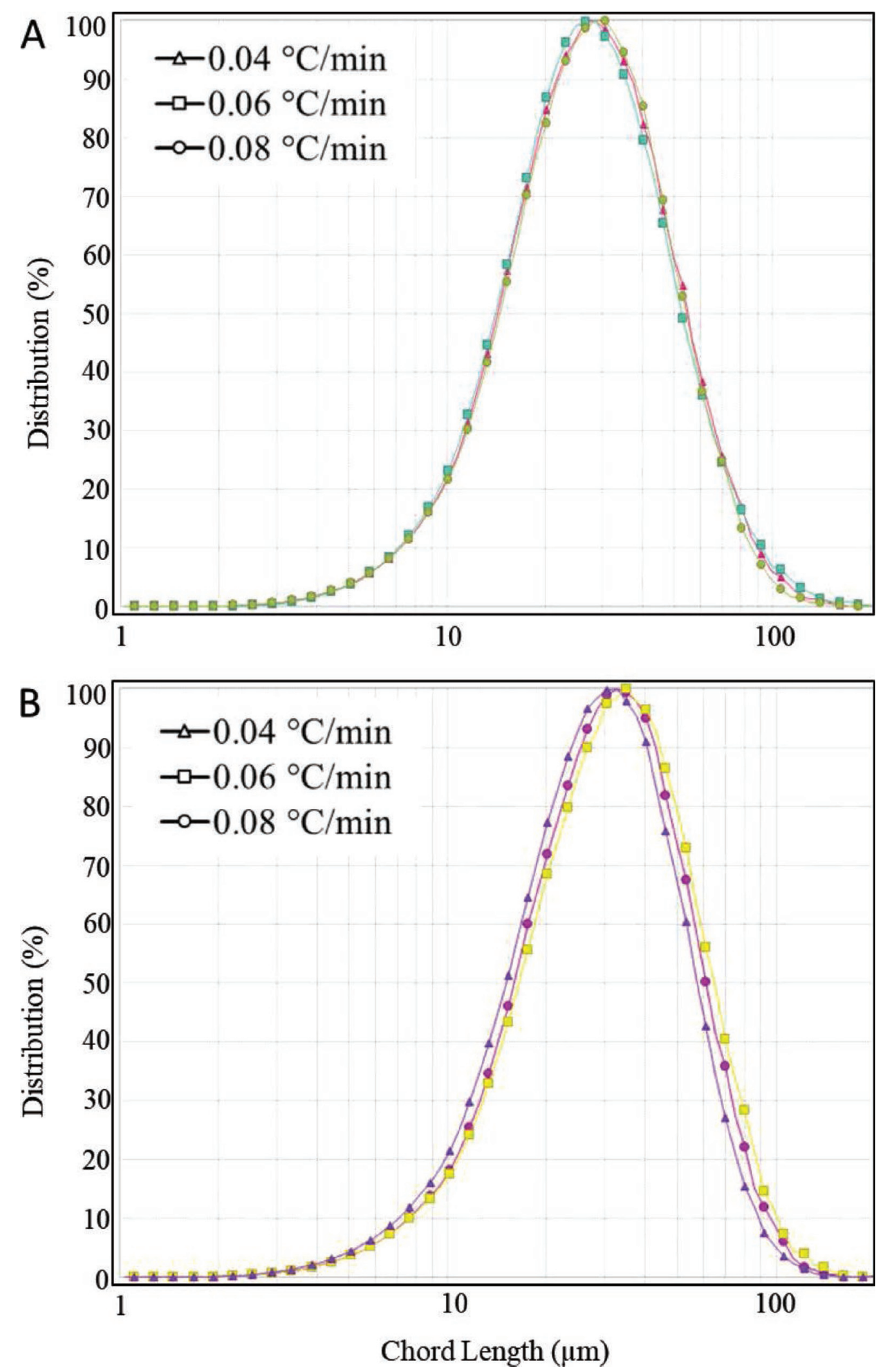

Figure 5. Particle chord length distribution (PCLD) data obtained from focused beam reflectance measurement (FBRM) at the end of lactose crystallization in (A) deproteinized whey (DPW) and (B) milk permeate powder (MPP) concentrates using $0.04^{\circ} \mathrm{C} / \mathrm{min}(\mathrm{slow}), 0.06^{\circ} \mathrm{C} /$ min (medium), and $0.08^{\circ} \mathrm{C} / \mathrm{min}$ (fast) cooling rates. Color version available online. 
Relatively higher lactose yield in the MPP concentrates was due to the increased supersaturation driving force compared with the DPW concentrate (Table 1).

\section{Characterization of Dried Lactose Crystals}

This section was focused to describe the influence of the slow, medium, and fast cooling rates on the quality of lactose crystals recovered from concentrated permeate after crystallization. Production of lactose crystals with minimum or no impurities is critical for economical industrial production to avoid further refining steps. Some of the impurities often present in whey and milk permeates are calcium phosphate, lactose phosphate, riboflavin, and potassium chloride (Lifran et al., 2007). Riboflavin tends to accumulate on the surface of lactose crystals and can be removed during the washing process. However, calcium phosphate and lactose phosphate are the impurities embedded into the crystalline lattice and cannot be washed off easily (Butler, 1998; Lifran et al., 2007). Hence, evaluating the extent of impurity deposition in the lactose crystals during different cooling rates is important for an efficient crystallization process.
Compositional Analysis. The protein and ash content in the lactose crystals recovered after crystallization and washing using the slow, medium, and fast cooling rates in the DPW concentrate were in the range of 0.66 to $0.78 \%$ and 1.35 to $1.46 \%$, respectively, as shown in Table 3. Although a trend was observed with percentage impurity decreasing as the cooling rate increased, no significant difference $(P>0.05)$ was observed in protein and ash content in 3 cooling rates.

On the other hand, ash content in lactose crystals recovered from the MPP concentrate was in the range of 2.46 to $2.52 \%$ with no significant difference observed between the 3 cooling rates. However, protein percentage was significantly high $(1.71 \%)$ in lactose crystals recovered after the crystallization using slow cooling rate. No significant difference was observed in the protein content in lactose crystals recovered from the crystallization using medium and fast cooling rates. The absence of rapid nucleation in MPP but the presence of high impurities in crystal mass imply that the deposition of impurities occurred during the lactose crystal growth. The MPP concentrates exhibited an early lactose crystal growth compared with the DPW concentrates as evident from large particle counts observed

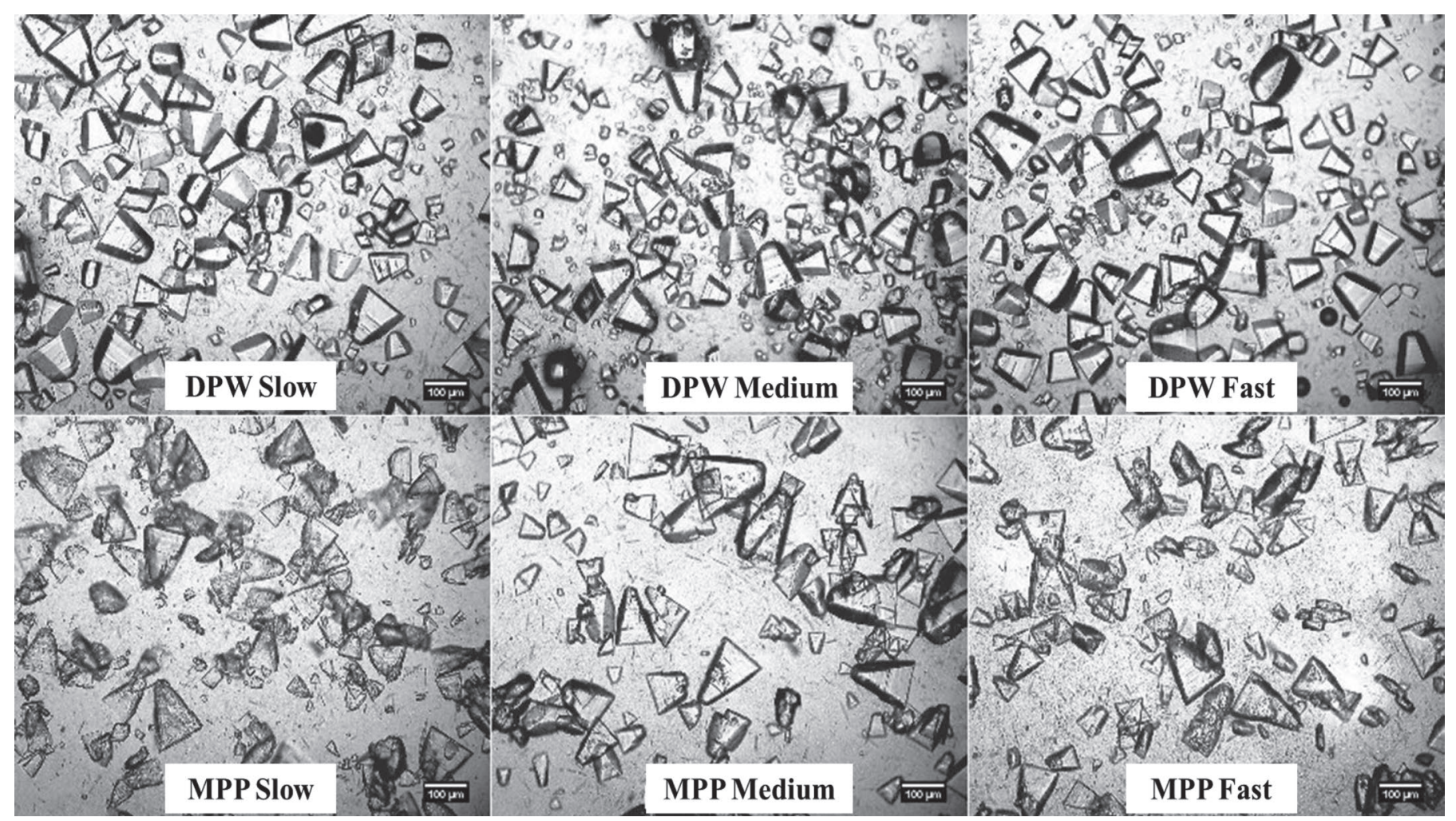

Figure 6. Microscope images of lactose crystals obtained at the end of lactose crystallization in deproteinized whey (DPW) and milk permeate powder (MPP) concentrates using $0.04^{\circ} \mathrm{C} / \mathrm{min}$ (slow), $0.06^{\circ} \mathrm{C} / \mathrm{min}$ (medium), and $0.08^{\circ} \mathrm{C} / \mathrm{min}$ (fast) cooling rates. 
from FBRM data (Figures $4 \mathrm{~B}$ and $4 \mathrm{D}$ ). According to Mackintosh and White (1974) and Butler (1998), the amount of impurities embedded in the crystal depends on the crystal growth rate and perfection of lactose crystal. This can be explained by increased accumulation of impurities from mother liquor on the edges of broken lactose crystals and crystals with cracks during crystal growth. The diffusion of lactose on the crystal lattice is relatively slow during longer cooling cycles and consequently increases the possibility of impurity inclusion in the lactose crystal, resulting in increased $\mathrm{K}, \mathrm{Ca}$, and $\mathrm{P}$ as impurities.

Crystal Purity. The microscopic analysis of lactose crystals to visualize the impurities was focused to interpret the location of impurities in the lactose crystal lattice and to identify if the impurity presence affected the tomahawk morphology. Calcium phosphate and lactose phosphate are the major impurities in the permeates that contribute toward a major fraction of impurities (Butler, 1998; Lifran et al., 2007). Lifran et al. (2007) observed changes to the tomahawk-shaped lactose crystals when the impurities such as lactose phosphate were incorporated at higher concentrations. Similar morphologies were observed in all the washed and dried lactose crystals recovered from both DPW and MPP concentrates at 3 cooling rates. From Figure 7 , it is evident that the lactose crystals were in tomahawk shape and a darker impurity region was mostly observed on the apex of tomahawk-shaped lactose crystals. The impurities, especially calcium phosphate, precipitated at $80^{\circ} \mathrm{C}$ and acted as a seed for heterogeneous nucleation. As the crystallization continued, crystal growth occurred toward the base region, leaving the impurities at the apex of the tomahawk-shaped crystal. Mineral content (Table 3) observed in the dried lactose crystals recovered from concentrated permeates also confirmed the theory that major impurities entrapped in the lactose crystal were composed of calcium and phosphate. These observations also supported the theory that higher large particle counts in FBRM data (Figures 4B and 4D) were contributed by mineral precipitates during common cooling of the concentrated permeates. Along with impurity inclusion at the apex, a few darker spots were present on the walls of crystals attributed to impurity inclusions during the crystal growth as well. Mother liquor and impurities tend to accumulate on the irregular sides of crystal walls and get trapped during crystal growth, resulting in impurity inclusion in the crystal on the sides of lactose crystal (Mackintosh and White, 1974; Butler, 1998). The microscopic image analysis of lactose crystals in Figure 7 also confirmed that the tomahawk shape was not disturbed by the extent of impurities trapped in the lactose crystal. This observation showed that reducing 


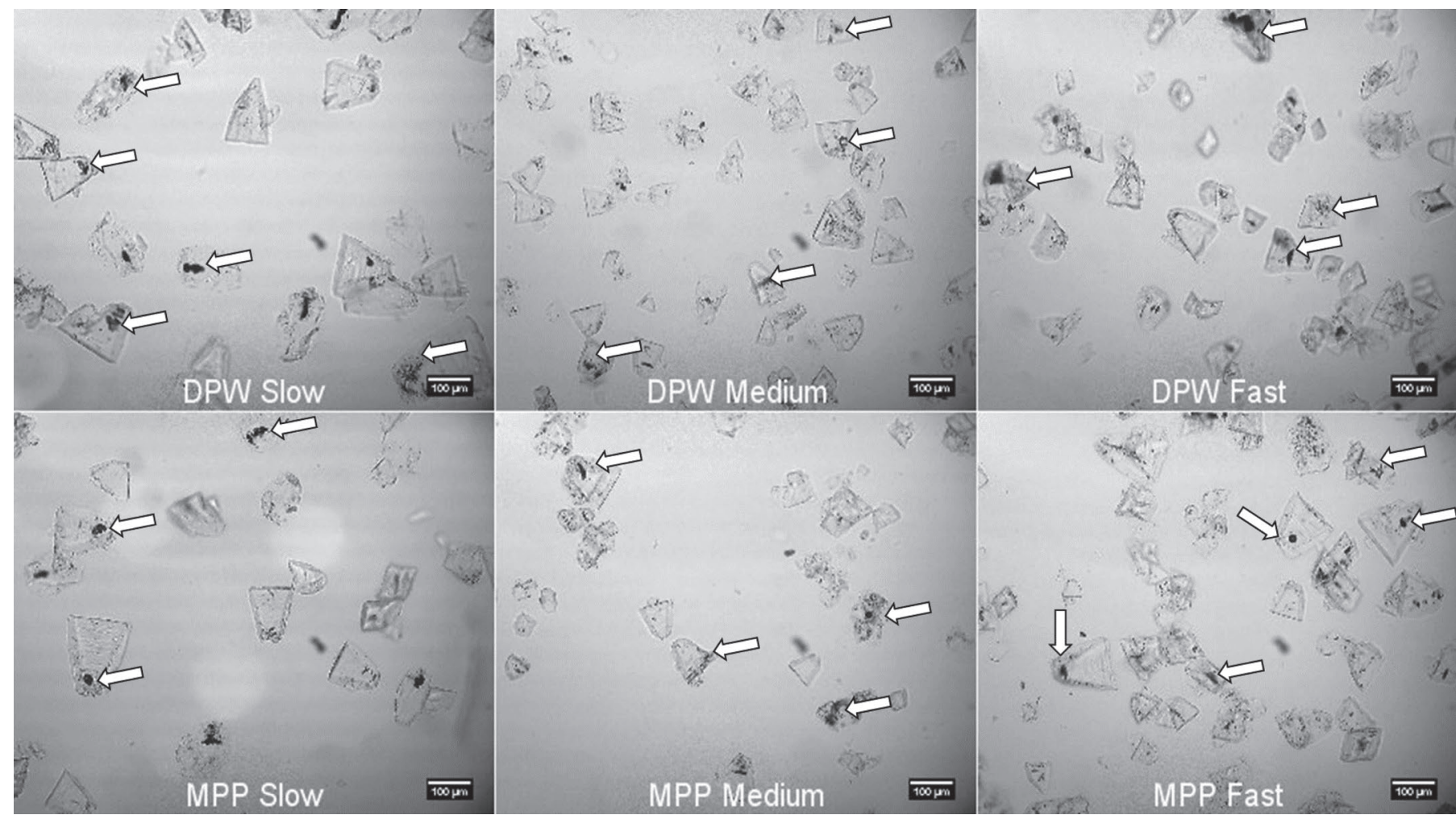

Figure 7. Lactose crystal purity images of dried lactose crystals recovered from lactose crystallization in deproteinized whey (DPW) and milk permeate powder (MPP) concentrates using $0.04^{\circ} \mathrm{C} / \mathrm{min}$ (slow), $0.06^{\circ} \mathrm{C} / \mathrm{min}$ (medium), and $0.08^{\circ} \mathrm{C} / \mathrm{min}$ (fast) cooling rates. Arrows indicate black spots representing impurities in the lactose crystals.

the crystallization time in this study did not influence the shape of lactose.

Differential Scanning Calorimetry. Thermal analysis of lactose crystals using calorimetry as shown in Figure 8 provided information about the presence of amorphous or crystalline lactose in the sample (Listiohadi et al., 2009). The absence of exothermic peaks in dried lactose crystals recovered from permeate concentrates, using 3 cooling rates, suggested the absence of amorphous lactose. Distinct endothermic peaks with enthalpies in the range of 86 to $89 \mathrm{~J} / \mathrm{g}$ and 108 to 110 $\mathrm{J} / \mathrm{g}$ were observed for lactose crystals recovered from DPW and MPP concentrates, respectively. Endothermic peak temperatures were observed in the range of 147 to $148^{\circ} \mathrm{C}$ for all the lactose crystals recovered at 3 cooling rates in DPW and MPP concentrates and attributed to the loss of crystalline water (Gombas et al., 2002). This observation further confirmed that $100 \%$ crystalline lactose was present in the lactose crystals recovered from concentrated permeates using the 3 cooling rates studied.

$\boldsymbol{F T I R}$. To identify the extent of lactose crystal purity, FTIR spectra of dried lactose crystals were compared with spectra of commercial lactose, DPW, and
MPP powders as shown in Figure 9. A less intense but broad peak at $1,650 \mathrm{~cm}^{-1}$ accompanied by a peak at $1,590 \mathrm{~cm}^{-1}$ was observed in lactose crystals recovered from both the DPW concentrates for the 3 cooling rates studied. The presence of a clear symmetric peak in commercial lactose at $1,650 \mathrm{~cm}^{-1}$ is associated with bending vibration of $\mathrm{O}-\mathrm{H}$ groups of water associated with lactose crystal (Nikanishi, 1962). Chandrapala et al. (2016) explained in a study related to the addition of lactic acid and calcium to the lactose model system that the intensity of these peaks was higher in presence of calcium and lactic acid when compared with the peak of pure lactose systems. They justified that the higher intensity of peaks at 1,590 and $1,650 \mathrm{~cm}^{-1}$ was due to restricted mobility of water molecules in the presence of calcium and lactic acid. The FTIR spectra of lactose crystals recovered from DPW concentrate using 3 cooling rates had no distinct differences in the peaks at 1,590 and $1,650 \mathrm{~cm}^{-1}$. A similar observation was made from the lactose crystals recovered from the MPP concentrate at the 3 cooling rates studied as well. The presence of these 2 peaks in DPW, MPP, and dried lactose crystals recovered from the concentrated permeates suggested that it is associated with the presence 

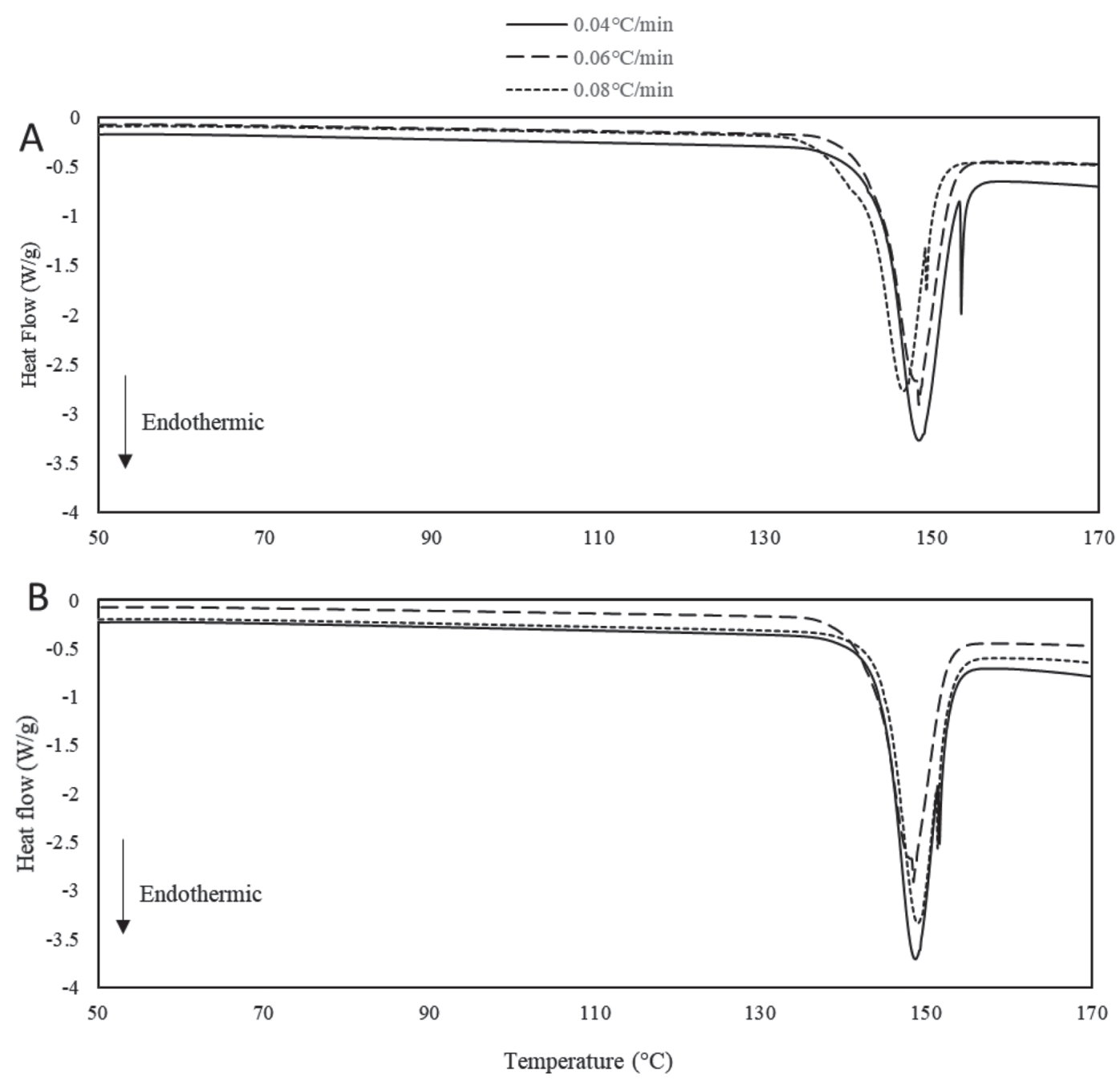

Figure 8. Differential scanning calorimetry thermograms obtained from dried lactose crystals recovered from lactose crystallization in (A) deproteinized whey (DPW) and (B) milk permeate powder (MPP) concentrates using $0.04^{\circ} \mathrm{C} / \mathrm{min}(\mathrm{slow}), 0.06^{\circ} \mathrm{C} / \mathrm{min}(\mathrm{medium})$, and $0.08^{\circ} \mathrm{C} /$ min (fast) cooling rates.

of impurities restricting the vibration of $\mathrm{O}-\mathrm{H}$ groups. Broad and intense peaks were observed in DPW and MPP spectra as compared with the clean symmetric peak at $1,650 \mathrm{~cm}^{-1}$ in commercial lactose. This observation strengthens the theory that the presence of impurities that restrict the $\mathrm{O}-\mathrm{H}$ groups had influence in the peaks of $1,590 \mathrm{~cm}^{-1}$ and $1,650 \mathrm{~cm}^{-1}$ wavenumber. This observation confirmed the fact that the recovered lactose crystals had fewer impurities compared with DPW and MPP powders, but the entrapped impurities in the crystals resulted in distorted peaks at 1,590 and $1,650 \mathrm{~cm}^{-1}$ wavenumber.

\section{CONCLUSIONS}

The effect of cooling rate during the crystallization process by measuring particle chord length data using
FBRM and lactose yield was investigated. Increasing the cooling rate from $0.04^{\circ} \mathrm{C} / \mathrm{min}$ to $0.06^{\circ} \mathrm{C} / \mathrm{min}$ and $0.08^{\circ} \mathrm{C} / \mathrm{min}$ had no significant difference in lactose yield and mean chord lengths of particles at the end of crystallization. Qualitative analysis of lactose confirmed that the purity of crystals was not affected by increasing the cooling rate from slow to medium or fast in concentrated permeates. Using medium or fast cooling rates could save the power and resources needed to run the crystallizer for 8 additional hours during crystallization of lactose in DPW and MPP concentrated permeates. As evident from the results so far, reducing the crystallization time by increasing the cooling rate within the range studied had no effect on quality of lactose crystals recovered from the DPW and MPP concentrates with the exception of significantly higher protein content in dried lactose crystals recovered after 
A

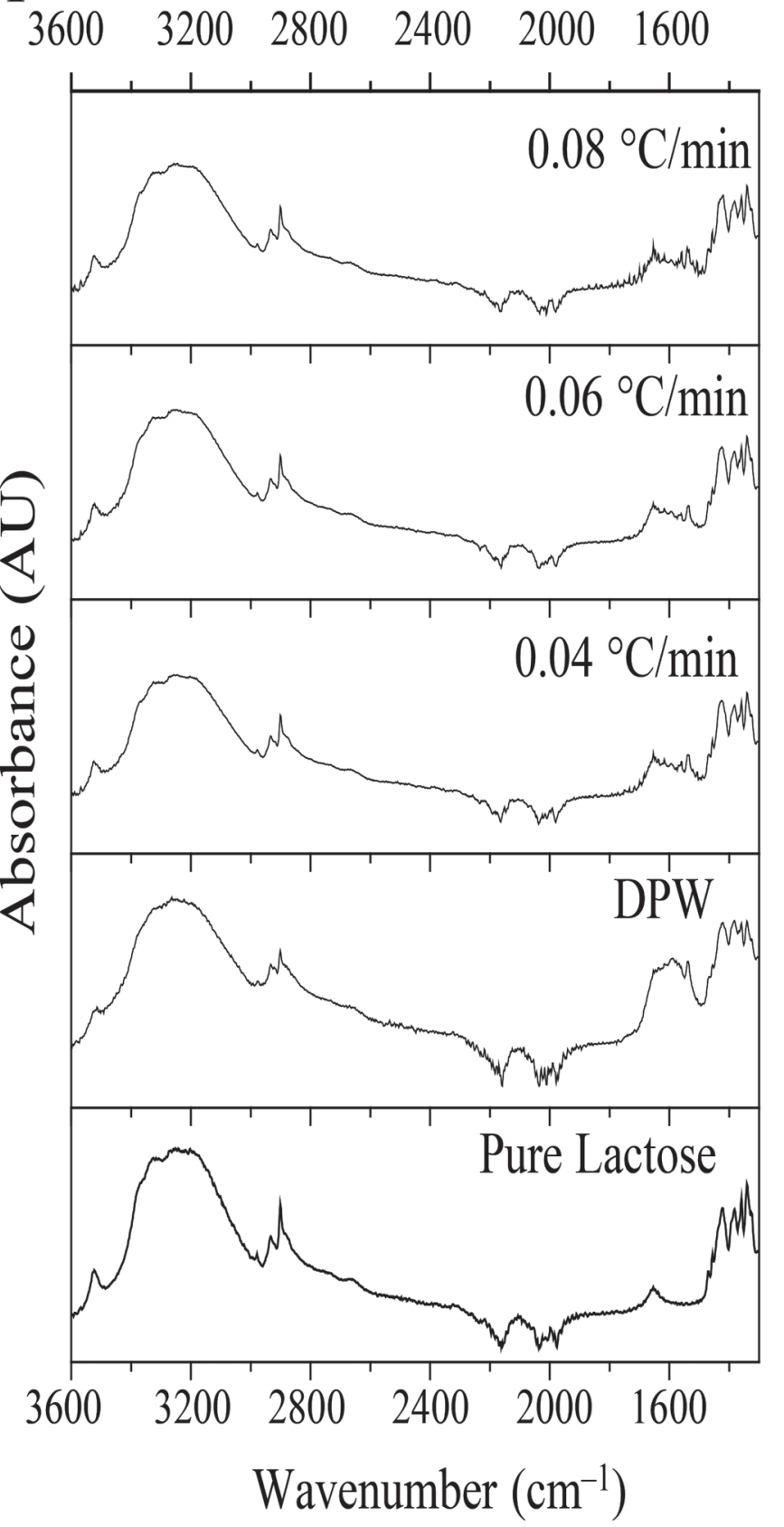

B $3600 \quad 3200 \quad 2800 \quad 2400 \quad 2000 \quad 1600$

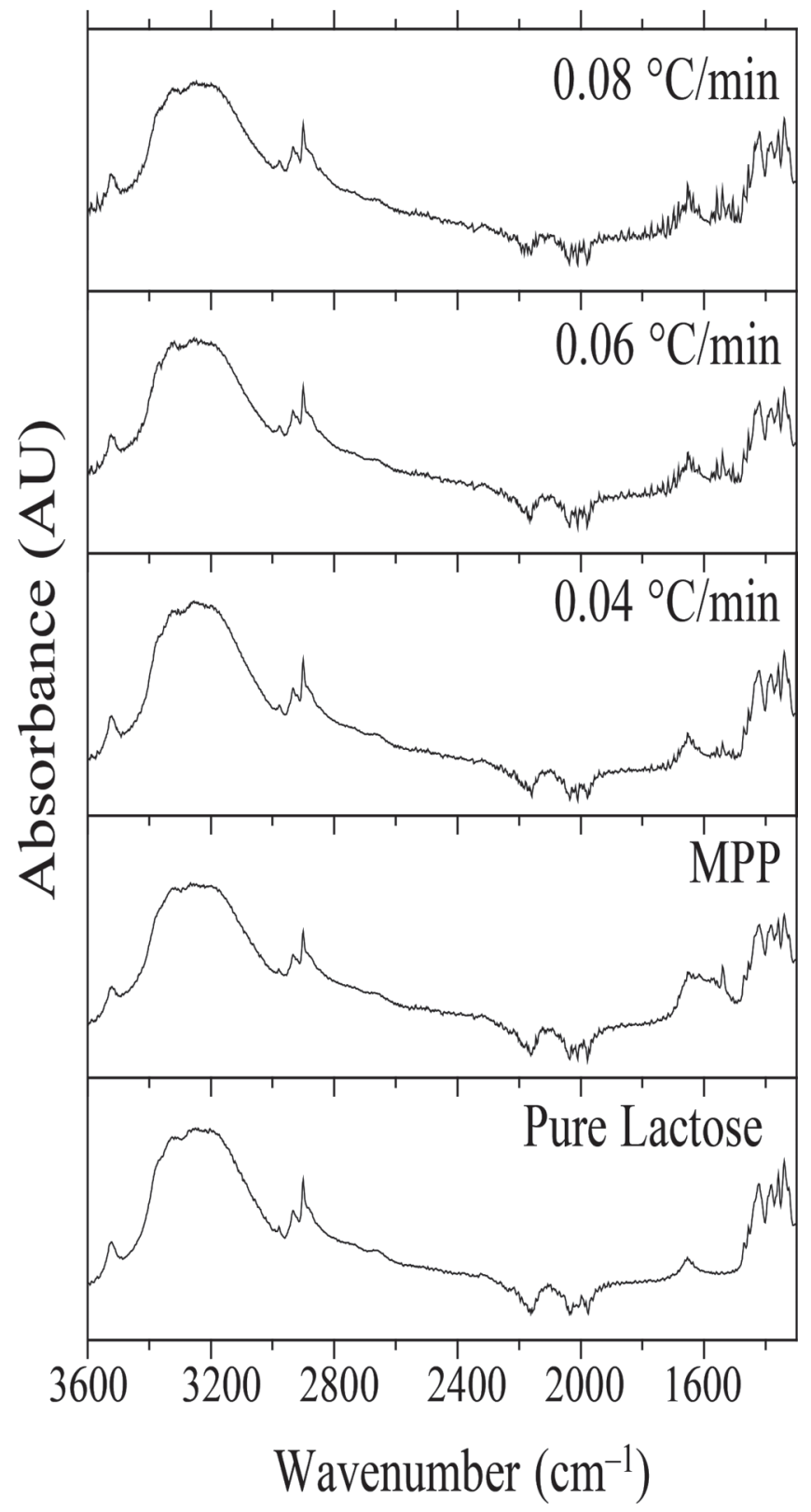

Figure 9. Fourier transform infrared spectroscopy (FTIR) acquired from dried lactose crystals recovered from lactose crystallization in (A) deproteinized whey (DPW) and (B) milk permeate powder (MPP) concentrates using $0.04^{\circ} \mathrm{C} / \mathrm{min}$ (slow), $0.06^{\circ} \mathrm{C} / \mathrm{min}(\mathrm{medium})$, and $0.08^{\circ} \mathrm{C} /$ min (fast) cooling rates. Fourier transform infrared spectra of pure lactose, DPW, and MPP to compare the peaks with dried lactose crystals recovered. $\mathrm{AU}=$ absorbance units.

MPP concentrate crystallized with slow cooling rate. These observations made from bench-top setup should be further confirmed by repeating this study on an industrial scale setup.

\section{ACKNOWLEDGMENTS}

This project is Kansas State Research and Extension (Manhattan) contribution number 18-363-J. 


\section{REFERENCES}

Amamcharla, J. K., and L. E. Metzger. 2011. Development of a rapid method for the measurement of lactose in milk using a blood glucose biosensor. J. Dairy Sci. 94:4800-4809.

AOAC International. 2002. Official methods of analysis. 17th ed. Association of Analytical Communities, Gaithersburg, MD.

Bhargava, A., and P. Jelen. 1996. Lactose solubility and crystal growth as affected by mineral impurities. J. Food Sci. 61:180-184.

Butler, B. 1998. Modelling industrial lactose crystallization. $\mathrm{PhD}$ Thesis. Department of Chemical Engineering, The University of Queensland, Australia.

Carpin, M., H. Bertelsen, A. Dalberg, C. Roiland, J. Risbo, P. Schuck, and R. Jeantet. 2017. Impurities enhance caking in lactose powder. J. Food Eng. 198:91-97.

Chandrapala, J., M. C. Duke, S. R. Gray, B. Zisu, M. Weeks, M. Palmer, and T. Vasiljevic. 2015. Properties of acid whey as a function of $\mathrm{pH}$ and temperature. J. Dairy Sci. 98:4352-4363.

Chandrapala, J., R. Wijayasinghe, and T. Vasiljevic. 2016. Lactose crystallization as affected by presence of lactic acid and calcium in model lactose systems. J. Food Eng. 178:181-189.

Gänzle, M. G., G. Haase, and P. Jelen. 2008. Lactose: Crystallization, hydrolysis and value-added derivatives. Int. Dairy J. 18:685-694.

Gombas, A., P. Szabó-Révész, M. Kata, G. Regdon, and I. Eros. 2002. Quantitative determination of crystallinity of $\alpha$-lactose monohydrate by DSC. J. Therm. Anal. Calorim. 68:503-510.

Goulart, D. B., and R. W. Hartel. 2017. Lactose crystallization in milk protein concentrate and its effects on rheology. J. Food Eng. 212:97-107.

IDF. 2002. Milk and milk products; Determination of nitrogen content-Routine method using combustion according to the Dumas principle. Standard No. 185. International Dairy Federation, Brussels, Belgium.

Lifran, E. V., T. T. L. Vu, R. J. Durham, J. A. Hourigan, and R. W. Sleigh. 2007. Crystallisation kinetics of lactose in the presence of lactose phosphate. Powder Technol. 179:43-54.

Listiohadi, Y., J. A. Hourigan, R. W. Sleigh, and R. J. Steele. 2009. Thermal analysis of amorphous lactose and $\alpha$-lactose monohydrate. Dairy Sci. Technol. 89:43-67.
Mackintosh, D., and E. White. 1974. The formation of inclusions in sugar crystals. AIChE Symposium Series. 72:11-20.

McLeod, J. 2007. Nucleation and growth of alpha lactose monohydrate. PhD Thesis. School of Engineering and Advanced Technology, Massey University, New Zealand.

McLeod, J., A. H. J. Paterson, J. R. Jones, and J. E. Bronlund. 2011. Primary nucleation of alpha-lactose monohydrate: The effect of supersaturation and temperature. Int. Dairy J. 21:455-461.

Mimouni, A., P. Schuck, and S. Bouhallab. 2005. Kinetics of lactose crystallization and crystal size as monitored by refractometry and laser light scattering: Effect of proteins. Lait 85:253-260.

Modler, H. W., and L. P. Lefkovitch. 1986. Influence of pH, Casein, and whey protein denaturation on the composition, crystal size, and yield of lactose from condensed whey. J. Dairy Sci. 69:684-697.

Mullin, J. W. 2001. Crystallization. 4th ed. Butterworth-Heinemann, Boston, MA.

Nikanishi, K. 1962. Infrared Absorption Spectroscopy-Practical. HoldeneDay Inc., San Francisco and Nankodo Company Limited, Tokyo, Japan.

Pandalaneni, K., and J. K. Amamcharla. 2016. Focused beam reflectance measurement as a tool for in situ monitoring of the lactose crystallization process. J. Dairy Sci. 99:5244-5253.

Shi, X., and Q. Zhong. 2014. Enhancing lactose crystallization in aqueous solutions by soluble soybean polysaccharide. Food Res. Int. $66: 432-437$.

Sunkesula, V., L. E. Metzger, and S. L. Beckman. 2017. Feasibility of soluble soybean polysaccharide for enhancing lactose crystallization during lactose manufacture. J. Dairy Sci. 100(Suppl. 2):11. (Abstr.)

US Dairy Export Council. 2015. US whey and milk permeate. Dairy Management Inc., Arlington, VA. Accessed Jul. 18, 2018. https:// www.thinkusadairy.org/assets/Documents/Customer\%20Site/ C1-Discover\%20US\%20Dairy/C1.3-Products/US\%20Whey-Milk -Permeate-Overview.pdf.

Wong, S. Y., R. K. Bund, R. K. Connelly, and R. W. Hartel. 2012. Designing a lactose crystallization process based on dynamic metastable limit. J. Food Eng. 111:642-654.

Wong, S. Y., and R. W. Hartel. 2014. Crystallization in lactose refining-A review. J. Food Sci. 79:R257-R272. 